\title{
The Influence of Early Sexual Debut and Sexual Violence On Adolescent Pregnancy: A Matched Case-Control Study In Jamaica
}

\begin{abstract}
CONTEXT: Contraceptive knowledge and use at first sex have increased over time among Jamaican adolescents, yet high unintended pregnancy rates persist. More information on risk factors for adolescent pregnancy is needed to inform programs.
\end{abstract}

METHODS: Structured interviews were conducted with 15-17-year-old females-250 who were currently pregnant and 500 sexually experienced, but never-pregnant, neighborhood-matched controls. Bivariate and multivariate analyses were used to examine associations between adolescent pregnancy and early sexual debut, sexual coercion or violence and sexual risk-taking behaviors.

RESULTS: Greater proportions of pregnant youth than of their never-pregnant peers reported having had first sex by age 14 (54\% vs. 41\%), a first sexual partner who was five or more years older (33\% vs. 20\%) or multiple partners (63\% vs. 50\%); a greater proportion of never-pregnant youth had used contraceptives at first sex ( $88 \%$ vs. $80 \%)$. Almost half (49\%) of all young women reported ever having experienced sexual coercion or violence. Compared with controls, pregnant youth had greater odds of having had an older partner at first sex and believing contraception is a woman's responsibility (odds ratios, 1.3 and 2.1, respectively), and had lower odds of ever having experienced sexual violence and thinking that it is important to protect oneself against pregnancy $(0.5$ and 0.2 , respectively). An interaction between early sexual debut and multiple partners was found. Having had multiple partners was associated with pregnancy only for youth with early sexual debut.

CONCLUSIONS: Encouraging adolescents to delay sexual debut and reduce their number of sexual partners may help prevent unintended pregnancies. Experiences of sexual coercion and violence were common among both groups, highlighting the need to address gender-based violence at the community level.

International Perspectives on Sexual and Reproductive Health, 2009, 35(1):21-28.

\section{By Joy Noel Baumgartner, Cynthia Waszak Geary, Heidi Tucker and Maxine Wedderburn}

Joy Noel Baumgartner is scientist I, Health Services Research; Cynthia Waszak Geary is senior director, Biomedical and Behavioral Research; and Heidi Tucker is biostatistician, Biostatistics Department-all with Family Health International, Research Triangle Park, NC, USA. Maxine Wedderburn is executive director, Hope Enterprises, Kingston, Jamaica.
Adolescent pregnancy continues to be a major public health problem in Jamaica. Despite widespread contraceptive knowledge and increased contraceptive use at first intercourse among Jamaican adolescents over the last decade (43\% in 1993 vs. $67 \%$ in 2002), 35\% of Jamaican women have their first pregnancy by age $19 .{ }^{1-3}$ Furthermore, among currently or ever-pregnant 15-19-year-olds, $88 \%$ of pregnancies are unintended. ${ }^{1}$ Adolescent pregnancy contributes to increased maternal and child morbidity and mortality, school dropout and a decreased likelihood of being gainfully employed. ${ }^{4-6}$ There is a need to more fully understand what factors beyond contraceptive knowledge and use influence unintended pregnancy among sexually active adolescents. This study examines risk factors for adolescent pregnancy in Jamaica by comparing pregnant adolescents with their sexually experienced, but never-pregnant, peers.

According to some studies, early sexual debut (commonly defined as having had first sexual intercourse at or before age 14) and experience of sexual coercion or violence contribute to unintended adolescent pregnancy. ${ }^{7-13}$ In Jamaica, the national Reproductive Health Survey (RHS) reports that 24\% of women aged 15-24 have had sexual intercourse by age 14 , and a community-based household survey of youth aged 15-19 found that 30\% of females had had sex before age 14.1,3,14,15 According to the Jamaica RHS, 20\% of sexually experienced 15-19-yearolds report ever being forced to have sex. ${ }^{1}$ Another study in Jamaica demonstrated a relationship between early sexual debut and childhood sexual abuse of young women. ${ }^{14}$ Early sexual debut may not only increase the length of time in adolescence in which a young woman can become pregnant, but is associated with experiences of sexual coercion and violence as well. $7,8,14,16-21$ Moreover, early sexual debut may lead to increased sexual risk-taking behavior, such as having multiple partners and not using contraceptives, and may be independently associated with pregnancy. $7,8,17,20,22,23$

Sexual coercion and sexual violence are receiving increased attention globally as health issues in their own right, and have been associated not only with early sexual debut, but with sexual risk-taking behavior and unintended pregnancy. ${ }^{9-13,15,16,20,21,24-27}$ Sexual coercion and sexual violence challenge young women's ability to control their own reproductive decision making and health. Of course, a direct link between sexual violence and un- 
wanted pregnancy exists when conception results from forced sex. However, adolescents who have been sexually coerced or abused at a young age may also be more likely than those who have not to continue patterns of sexual victimization and sexual risk-taking behavior throughout life, including a lack of self-protective behavior (e.g., reducing number of partners, using contraceptives), thus highlighting the indirect link between sexual violence and unintended pregnancy. ${ }^{28,29}$

The term sexual violence commonly refers to sexual intercourse that is physically forced (rape or being held down, hit or threatened). Sexual coercion has been defined in the literature more broadly as the "act of forcing (or attempting to force) another individual through violence, threats, verbal insistence, deception, cultural expectations or economic circumstance to engage in sexual behavior against his or her will." ${ }^{28}$ Definitions that aggregate all forms of sexual coercion and sexual violence make it difficult to establish a relationship between adolescent pregnancy and sexual violence, such as rape, or sexual coercion, which adolescents may or may not identify as violence. Significant associations between sexual coercion and adolescent pregnancy have been shown in both developing $9,10,14$ and developed countries; ${ }^{16,26}$ however, studies linking sexual violence and pregnancy in the United States have yielded conflicting results. ${ }^{25,30}$ In this study, we distinguish three categories for describing a sexual experience: willing, persuaded or coerced, and forced. These more nuanced measures may help contribute to a better understanding of whether sexual coercion and sexual violence are associated with adolescent pregnancy in Jamaica.

Additional factors found to be associated with adolescent pregnancy include physical abuse by an intimate partner, experience of family violence and, in Jamaica specifically, low self-esteem and the absence of a father figure. ${ }^{31-33}$

In this study, we compare the magnitude of the relationships between early sexual debut and sexual coercion or violence among pregnant adolescents to that among their sexually active, but never-pregnant, peers. We also examine whether and how sexual risk-taking behaviors (i.e., multiple sexual partners and nonuse of contraceptives) are associated with pregnancy. Specifically, we investigate whether early debut and sexual coercion or violence are positively associated with pregnancy, and if so, whether the relationships are direct or mediated through increased sexual risk behaviors.

\section{METHODS}

\section{Data Collection}

We conducted a matched (1:2) case-control study of pregnant adolescents who attended antenatal care clinics in Kingston, Jamaica, and their sexually experienced, but never-pregnant, neighborhood-matched peers. Pregnant adolescents aged 15-17 were recruited from seven public sector antenatal care clinics in Kingston parish (health region 1), including the main hospital (tertiary center) in Kingston; clinics were selected in consultation with the Jamaican Ministry of Health. In the Jamaica health system, all pregnant women younger than 18 are considered to be at high risk and are referred to a tertiary center for continued antenatal care. Use of antenatal care is nearly universal (99\%) among pregnant women in Jamaica. ${ }^{1}$ Recruitment through clinics reduced ethical concerns about confidentiality, as the adolescents had already selfidentified as pregnant. Trained interviewers recruited potential participants who had a fetal gestational age of up to 35 weeks from clinic waiting rooms. Interviews were conducted in private locations within the health facilities to maintain privacy. Interviewers asked recruited young women for their home address to identify the corresponding census enumeration districts in which they lived; participants were assured that their households would not be contacted for any reason.

For each participating pregnant adolescent, we recruited two sexually experienced, never-pregnant 15-17-yearold controls matched by neighborhood (i.e., enumeration district), so that cases and controls were likely to have similar socioeconomic characteristics. To select controls, interviewers systematically contacted households from a predetermined starting point within each matched neighborhood; only one young woman per household was interviewed. During the initial household contact, potential participants were told that the study was about adolescent female health; more specific information was given during the consent process. All interviews were held at participants' residences, but not necessarily within the homes if the participant deemed it inappropriate: For example, some interviews were conducted in the yard or under a tree, where privacy could be ensured.

Written informed consent was obtained from each participant prior to administration of the structured questionnaires. Participants received J $\$ 750$ (US\$12) for their participation. Participation was voluntary, information was kept confidential and World Health Organization (WHO) guidelines for conducting research on violence against women were followed. ${ }^{34,35}$ As those guidelines suggest, a parental waiver for consent was obtained, so that only the participants themselves were fully informed about the content of the interview, to reduce the risk of harm to study participants. Clinic staff and family members were told only that the study was about adolescent female health. The study received ethical approval from Family Health International's Protection of Human Subjects Committee and Jamaica's Advisory Panel on Ethics and Medico-Legal Affairs in the Ministry of Health.

Interviewers received training about sexual violence, including information on services available for victims. If participants disclosed experiences of violence, interviewers offered information about where they could go for support and services. The study arranged for a local psychologist to be available for short-term counseling as needed. Appropriate referrals were made if the interviewer thought that a participant was in need of additional services.

Of the 250 pregnant women recruited to participate in the study, 182 were from one large hospital and the rest 
from smaller antenatal care clinics (range: 5-21 per clinic). The refusal rate among potential cases was $15 \%$. A total of 500 self-reported never-pregnant, neighborhoodmatched controls were recruited. Only one potential control refused to participate.

\section{Variables}

Our questionnaires were pretested and included closedended questions about respondents' social and demographic background, parental presence and support, exposure to violence and drug use in the home, and their involvement in the community. Interviews also included the well-established Rosenberg self-esteem scale and the Center for Epidemiologic Studies depression scale. ${ }^{36,37}$ The scales were coded such that higher scores on the scales indicate more negative attributes (i.e., more depressed and lower self-esteem).

Young women were asked a series of questions about their first and most recent sexual intercourse experiences, attitudes about gender roles and ideas about pregnancy (e.g., pregnancy intention and feelings about becoming pregnant). We defined early sexual debut as having had first sexual intercourse at or before age 14; we defined multiple partners as having had two or more lifetime sexual partners. Because ever-use of contraceptives, including condoms, was common among cases and controls (95\% and $97 \%$, respectively), we used contraceptive use at first sex as the primary measure of unprotected sex. Relationship status was coded as married, single in stable relationship and living with boyfriend, single in stable relationship and not living with boyfriend, single in a casual relationship and single not currently in a relationship; a stable relationship was defined as any of the first three responses.

Young women were also asked a range of questions regarding their experiences of sexual coercion and sexual violence. Regarding their first and most recent sexual experiences, participants were asked whether they had been willing (i.e., wanted to have sex), persuaded (i.e., did not really want to have sex, were not sure, were talked into it or had sex out of fear of being abandoned otherwise), or forced or raped (i.e., was physically forced, held down, hit or threatened). "Persuaded" was used in the questionnaire because during pretesting, "coerced" was not understood. In addition, women were asked if they had ever been physically forced to have sex, ever had sex because of being afraid or ever had degrading sex; interviewers did not define "degrading" for participants. From these questions, we developed three composite variables: ever experienced sexual coercion (coercion at first or last sex, sex out of fear), ever experienced sexual violence (violence at first or last sex, ever physically forced to have sex, ever had degrading sex) and ever experienced sexual coercion or violence (combination of previous two composite variables).

We included the variable "ever been touched in a way that was not right or comfortable" because this variable had been used in a previous Jamaican survey that tried to measure sexual coercion. ${ }^{36}$ This variable was highly correlated with the three sexual coercion and violence variables, and so was not studied separately. In addition, because the question was subjective, it could reflect, for some participants, their comfort with physical contact or intimacy, whereas sexual coercion and sexual violence were more clearly defined for the participants. Thus, although this variable was used for power calculations, it was not used in any other analyses.

The variables analyzed included experienced sexual coercion or violence at first sex, ever experienced sexual coercion, ever experienced sexual violence and ever experienced sexual coercion or violence.

\section{Data Analysis}

Our sample (250 cases and 500 controls) has $80 \%$ power to detect an odds ratio (cases vs. controls) of at least 1.6 (statistically significant at alpha=.05) for "ever been touched in a way that was not right or comfortable," assuming $41 \%$ prevalence in the control group. ${ }^{38}$ The prevalence estimate in the control group was obtained from a 2000 United Nations Population Fund adolescent study conducted in Jamaica that included the "ever touched" question as an attempt to assess sexual coercion. ${ }^{36}$ We could not identify any other studies in Jamaica that collected prevalence data on sexual coercion. The study also has sufficient power to detect reasonable odds ratios (e.g., about 2.0) for first sex being against the youth's will, assuming $17 \%$ prevalence in the control group.

Data were analyzed with SAS version 9.1. To get a general understanding of associations prior to modeling, we performed bivariate Mantel-Haenszel chi-square tests comparing groups' (pregnant vs. never-pregnant) social and demographic variables and the main variables of interest (early sexual debut, sexual coercion or violence, having had two or more lifetime sexual partners and contraceptive use at first sex). Except for this preliminary analysis, the primary method of analysis was conditional logistic regression, stratifying on the matched case-control set to take matching into account.

Model development was a multistage process. First, univariate conditional logistic regression models were fitted to determine which variables were potentially associated with pregnancy. Covariates found to be significant at the $\mathrm{p}<0.10$ level were included in multivariate conditional logistic regression models; early sexual debut, sexual coercion or violence, having had two or more lifetime sexual partners and contraceptive use at first sex were included in the models regardless of statistical significance, because of their theoretical importance. In addition, all multivariate models included age, to control for length of exposure; controlling for number of years sexually active led to comparable results (data not shown).

After checking for collinearity among independent variables, we conducted models separately for each main variable of interest, controlling for age and all significant covariates, to assess potential confounding. We also tested 
TABLE 1. Descriptive statistics of pregnant and never-pregnant women aged 15-17, Kingston, Jamaica

\begin{tabular}{|c|c|c|c|}
\hline Characteristic & $\begin{array}{l}\text { All } \\
(\mathrm{N}=750)\end{array}$ & $\begin{array}{l}\text { Pregnant } \\
(\mathrm{N}=250)\end{array}$ & $\begin{array}{l}\text { Never-pregnant } \\
(\mathrm{N}=500)\end{array}$ \\
\hline \multicolumn{4}{|l|}{ Social and demographic } \\
\hline Mean age (yrs.) & 16 & 16 & 16 \\
\hline$\geq$ secondary education & 96 & 96 & 96 \\
\hline Worked in last 4 wks. & 7 & 5 & 9 \\
\hline Lived in community <3 yrs. & 20 & 24 & $17^{*}$ \\
\hline Involved in area clubs/community groups & 20 & 14 & $23^{* *}$ \\
\hline Actively practices a religion & 33 & 34 & 32 \\
\hline Currently lives with fathert & 24 & 20 & $26^{*}$ \\
\hline Currently lives with mothert & 66 & 61 & $69^{*}$ \\
\hline Father gives both emotional/financial support & 44 & 40 & 47 \\
\hline Mother gives both emotional/financial support & 81 & 76 & $83^{*}$ \\
\hline Drank alcohol in last 4 wks. & 23 & 4 & $32^{* *}$ \\
\hline Someone at home uses alcohol & 66 & 64 & 67 \\
\hline Someone at home uses ganja & 44 & 47 & 42 \\
\hline Ever experienced familial violence at home & 17 & 14 & 18 \\
\hline Does not feel safe at home & 12 & 10 & 13 \\
\hline Depression score $\geq$ median $($ range, $20-80) \S$ & 50 & 57 & $47^{*}$ \\
\hline Self-esteem score $\geq$ median (range, 10-40) †† & 50 & 61 & $45^{* *}$ \\
\hline Relationship with parents/guardian is good/very good & 64 & 65 & 63 \\
\hline Believes contraception is woman's responsibility & 16 & 21 & $13^{* *}$ \\
\hline Thinks it very important to protect self against pregnancy & 96 & 91 & $98^{* *}$ \\
\hline Worried more about HIV/STIs than pregnancy & 95 & 95 & 95 \\
\hline 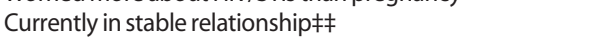 & 82 & 87 & $80^{*}$ \\
\hline \multicolumn{4}{|l|}{ Sexual } \\
\hline Mean age at first sex (range, 11-17) & 15 & 14 & 15 \\
\hline Early sexual debut ( $\leq 14$ yrs.) & 45 & 54 & $41^{* *}$ \\
\hline First sexual partner $>5 \mathrm{yrs}$. older & 24 & 33 & $20^{* *}$ \\
\hline Used contraceptive at first sex & 86 & 80 & $88^{* *}$ \\
\hline Mean lifetime no. of sexual partners (range, $1-50$ ) & 2 & 2 & 2 \\
\hline$\geq 2$ lifetime sexual partners & 54 & 63 & $50^{* *}$ \\
\hline \multicolumn{4}{|l|}{ Experience of sexual coercion/violence } \\
\hline \multicolumn{4}{|l|}{ Participation at first sex } \\
\hline Willing & 66 & 66 & 66 \\
\hline Persuaded/coerced & 27 & 26 & 27 \\
\hline Forced & 6 & 6 & 7 \\
\hline \multicolumn{4}{|l|}{ Participation at last sex } \\
\hline Willing & 90 & 91 & 89 \\
\hline Persuaded/coerced & 8 & 7 & 8 \\
\hline Forced & 2 & 2 & 3 \\
\hline Ever physically forced to have sex & 23 & 19 & 25 \\
\hline Ever had sex when did not want to/afraid not to have sex & 19 & 19 & 19 \\
\hline Ever forced to do something sexually degrading & 6 & 6 & 6 \\
\hline Ever received money/gifts for sex & 7 & 6 & 7 \\
\hline Ever touched in an uncomfortable way & 59 & 51 & $63^{* *}$ \\
\hline Ever experienced intimate partner physical violence & 33 & 33 & 33 \\
\hline Ever experienced intimate partner emotional abuse & 40 & 39 & 41 \\
\hline \multicolumn{4}{|l|}{ Coercion/violence } \\
\hline Ever experienced sexual violence & 27 & 22 & $29^{*}$ \\
\hline Ever experienced sexual coercion & 40 & 38 & 40 \\
\hline Ever experienced sexual coercion or violence & 49 & 46 & 51 \\
\hline
\end{tabular}

${ }^{*} p \leq .05$. ${ }^{*} p \leq .01$. †Not mutually exclusive. ¥Marijuana. \$Median $42 ;$ a higher score indicates being more depressed. ††Median 21; a higher score indicates having lower self-esteem. ¥¥May or may not be living with partner. Note: All figures are percentages, unless noted.

several definitions of coercion or violence to determine the one with the strongest association with pregnancy. After confirming no confounding and selecting the best measure of violence, we tested selected interactions among the variables in the model.

The final model consisted of the main variables of interest, age, all significant covariates and one significant interaction (early sexual debut $\mathrm{x}$ having had two or more lifetime sexual partners). We explored the interaction further by conducting two additional analyses-one for women who had had an early debut and another for those who had not-examining the association between pregnancy and multiple partners. All p values are two-tailed and not corrected for multiple analyses.

\section{RESULTS \\ Descriptive Analyses}

Among the pregnant participants, 18 (7\%) reported being pregnant for the second time, and one $(0.4 \%)$ for the third. Almost all (94\%) stated that their pregnancies were unintended, and two-fifths (41\%) said that they had been using contraceptives when they became pregnant, primarily condoms (87\%). Eighty percent said that they were unhappy when they learned that they were pregnant, and 94\% said that it was not the right time to get pregnant and that they should have been older.

Pregnant and never-pregnant young women differed in their social and demographic characteristics (Table 1). Greater proportions of pregnant young women than of their never-pregnant peers had lived in their community for less than three years (24\% vs. $17 \%$ ); scored at or above the median on the depression scale (57\% vs. 47\%); scored at or above the median on the self-esteem scale (61\% vs. $45 \%$ ), indicating lower self-esteem; believed that contraception is the woman's responsibility ( $21 \%$ vs. $13 \%$ ); and were currently in a stable relationship ( $87 \%$ vs. $80 \%$ ).

Smaller proportions of pregnant youth than of neverpregnant youth were involved in area clubs or community groups (14\% vs. 23\%), were currently living with their father (20\% vs. $26 \%$ ), were currently living with their mother (61\% vs. 69\%), were receiving emotional and financial support from their mother (76\% vs. $83 \%$ ) and had drunk alcohol within the last four weeks (4\% vs. 32\%). Although the vast majority of both pregnant and never-pregnant women thought that protecting themselves from pregnancy was important, that proportion was higher among never-pregnant women (98\% vs. 91\%).

There were also some differences found between pregnant and never-pregnant youth in terms of their sexual characteristics. A greater proportion of pregnant women had first had sex by age 14 ( $54 \%$ vs. $41 \%$ ), had a first sexual partner who was at least five years older (33\% vs. 20\%) and had had two or more lifetime sexual partners (63\% vs. $50 \%$ ). A greater proportion of never-pregnant women than of their pregnant peers had used contraceptives at first sex ( $88 \%$ vs. $80 \%$ ).

One-third of all participants stated that they had been persuaded or forced to participate in their first sexual experience; fewer (10\%) had been unwilling at last sex. Among the sexual coercion or violence variables, only two differed significantly between groups. A greater proportion of never-pregnant youth than of pregnant youth reported ever having been touched in an uncomfortable way (63\% vs. $51 \%$ ) and having ever experienced sexual violence ( $29 \%$ vs. 22\%). About half of all participants had ever experienced sexual coercion or violence (49\%), and more than a quarter (27\%) had ever experienced some form of sexual violence, including forced or degrading sex. 


\section{Multivariate Analyses}

In multivariate analyses, pregnant youth had greater odds than their never-pregnant peers of being in a stable relationship, scoring higher on the self-esteem scale (i.e., having lower self esteem), having had a partner at first sex who was more than five years older and believing that contraception is the woman's responsibility (odds ratios, 1.3-2.1; Table 2). Pregnant women had lower odds than those who had never been pregnant of ever experiencing sexual violence, being involved in clubs or community groups and thinking it is very important to protect oneself against pregnancy (0.2-0.6). The negative association between pregnancy and ever having experienced sexual violence was unexpected. Investigation of possible confounders did not uncover an explanation (not shown).

In addition, a significant interaction was found between early sexual debut and lifetime number of partners (Table 3). Among young women who had had their first sexual intercourse by age 14, those who were pregnant had greater odds of having had two or more lifetime sexual partners, than those who had never been pregnant (odds ratio, 3.2). No such association was found among those who had not had an early sexual debut.

\section{DISCUSSION}

On the basis of the literature, we had anticipated that pregnant adolescents would be more likely than their neverpregnant peers to have had an early sexual debut and to have ever experienced sexual coercion or violence. According to our results, early sexual debut was positively associated with pregnancy only in combination with having two or more lifetime sexual partners; ever-experience of sexual violence was negatively associated with pregnancy.

Having multiple partners was a risk factor for pregnancy among adolescents with an early sexual debut, but not among those who first had sex later. It may be that these two groups represent different subpopulations; the fact that some covariates were associated with pregnancy for one group but not for the other lends some (albeit post-hoc) support for this idea. Alternatively, it may be that because our age range is small, youth whose first sex occurred after age 14 simply had not yet had time to have more than one partner. For example, we did not obtain information that would let us determine whether multiple partnerships were serial, concurrent, transactional or affection-based relationships. The nature of the multiple partnerships may have differed between participants with early and later debut and this, in turn, may have influenced contraceptive use and subsequent pregnancy risk. The type of partnership could also dictate the frequency of sex and the young woman's negotiating power for condom use.

Overall, reporting at least one experience of sexual coercion or violence was common and differed little between pregnant and never-pregnant youth. For many participants, their first sex was coerced or forced and, therefore, the timing of their sexual debut was not a choice. We were not able to uncover an explanation for the negative association be-

TABLE 2. Odds ratios (and 95\% confidence intervals) from conditional logistic regression analyses comparing odds of reporting selected variables for pregnant women versus never-pregnant women, controlling for all other variables $(N=750)$

Variable

$\geq 2$ lifetime sexual partners

Early sexual debut $x$ multiple partners (interaction term)

Ever experienced sexual violence

Used contraceptive during first sex

Age

Currently in stable relationship

Currently lives with father§

Currently lives with mother§

Mother gives both emotional/financial support

Lived in community $<3$ yrs.

Involved in area clubs/community groups

Depression score $\geq$ median

Self-esteem score $\geq$ median

First sexual partner $>5$ yrs. older

Believes contraception is woman's responsibility

Thinks it very important to protect self against pregnancy

${ }^{*} p \leq .05$. ${ }^{*} p \leq .01$. In the presence of the interaction term, these variables are not interpretable. \$Statistically significant interaction; see Table 3. \$Not mutually exclusive.

Odds ratio

$+$

$+$

$\neq$

$0.49(0.32-0.75)^{* *}$

$0.69(0.40-1.16)$

$0.94(0.73-1.21)$

$1.93(1.16-3.22)^{* *}$

$0.73(0.47-1.14)$

$0.77(0.50-1.18)$

$0.85(0.52-1.38)$

$1.22(0.78-1.92)$

$0.56(0.33-0.93)^{*}$

$1.12(0.76-1.64)$

$2.07(1.38-3.10)^{* *}$

$1.29(1.12-1.48)^{* * *}$

$2.05(1.27-3.31)^{* *}$

$0.22(0.09-0.55)^{* *}$
Early sexual debut ( $\leq 14$ yrs.)

tween pregnancy and sexual violence. However, although the odds of ever having experienced sexual violence differed significantly between pregnant and never-pregnant youth, there was no significant difference in any other coercion or violence variable, except for ever having been touched in an uncomfortable way, which, being more subjective, may reflect differences in comfort about being touched.

Although the negative relationship between pregnancy and sexual violence may be related to unmeasured factors, there are a few possible explanations. Because pregnant youth were more likely than others to be in stable relationships and living with their partners, they may have had slightly more fear of retaliation if reports of violence got back to their partner and, therefore, may have been more likely than other respondents to underreport violence. Also, although all participants were underage, pregnant youth may have underreported intimate partner violence because there are legal requirements for mandatory reporting of violence to social services by health providers. Finally, more recent studies have shown pregnancy itself to be protective against violence, so pregnant youth may have had less time to be exposed to violence, compared with their never-pregnant peers. ${ }^{39}$

With the cross-sectional, case-control design, we cannot

TABLE 3. Odds ratios (and 95\% confidence intervals) from conditional logistic regression analyses comparing the odds of having had two or more lifetime sexual partners for pregnant versus never-pregnant women, separately for those with early sexual debut and later debut

\begin{tabular}{lll} 
Subgroup & Variable & Odds ratio \\
\hline $\begin{array}{l}\text { Early debut }(\mathrm{N}=339) \\
\begin{array}{l}\text { Pregnant (vs.never- } \\
\text { pregnant) }\end{array}\end{array}$ & $\geq 2$ lifetime partners & $3.23(1.22-8.56)^{*}$ \\
$\begin{array}{l}\text { Later debut }(\mathrm{N}=408) \\
\begin{array}{l}\text { Pregnant (vs.never- } \\
\text { pregnant) }\end{array}\end{array}$ & $\geq 2$ lifetime partners & $0.88(0.38-2.07)$ \\
\hline$*$ $<<.05$. Note: Each model controls for the covariates listed in Table 2.
\end{tabular}


establish directionality of cause and effect: Pregnant participants may be less involved in clubs, more depressed and have lower self-esteem, for example, because of the pregnancy itself. In addition, two variables significantly associated with pregnancy-having a first sexual partner who was five or more years older and believing that contraception is the woman's responsibility-could represent a lack of power or an unequal relationship. Although the age of first partner would have been determined prior to pregnancy, believing contraception is the woman's responsibility could have preceded the pregnancy, potentially representing a lack of power, or it could have been a consequence of getting pregnant and believing that she should have been more responsible for practicing contraception. Being in a stable relationship may be an indicator of more regular sex and increased risk of pregnancy, but getting pregnant may have changed a relationship from casual to stable. In addition, stable relationships may reflect less condom use due to ideas of faithfulness or an ambivalent desire for pregnancy, even though the vast majority of pregnancies were unintended.

\section{Limitations}

This study has several limitations that need to be taken into consideration. First, our results are not necessarily generalizable beyond an urban Jamaican population. Second, many of our measures were based on self-report. Thus, it is possible that some youth who reported never having been pregnant in fact had had (illegal) abortions or miscarriages that they chose not to report. If there was underreporting of abortion among the never-pregnant participants, this may partially account for the unusual relationship between pregnancy and violence. We also do not know if violence was more likely to be underreported by pregnant youth than by never-pregnant youth. Participants who had ever experienced sexual violence may have been more likely than others to have aborted unintended pregnancies and then been reluctant to share that information. Third, we were not able to adequately examine lack of contraceptive use as a risk factor for pregnancy because of the very similar and high levels of reported condom use at first sex and ever-use among both cases and controls, yet differences in correct and consistent condom use may be the key to pregnancy prevention. We did not attempt to measure recent contraceptive use due to the different contraceptive needs of pregnant and nonpregnant youth. Finally, we did not measure frequency of sex, which has been shown to correlate with adolescent pregnancy in at least one South African study that also examined sexual violence. ${ }^{9}$ It is possible that for our sample, those who had ever experienced sexual coercion or violence preferred less frequent sex, thereby reducing their pregnancy risk.

\section{Conclusions}

Specific to pregnancy risk, delaying sexual debut and discouraging multiple partnerships will help prevent adolescent pregnancy, but that means focusing on prevention prior to sexual debut. Encouraging adolescents to delay sex (if it is under their control) until finished with school or employed, for example, is an appropriate message. Among sexually active young women, increasing the use of more reliable, hormonal contraceptive methods (or supporting dual method use) may also help reduce pregnancy risk. Indicators of unequal relationships (partner age difference, not sharing contraceptive responsibility) need to be addressed in pregnancy prevention efforts, and gender-based violence, which appears to be widespread among this study population, should be addressed at the community level. Future research could test specific pathways for how early debut and lifetime number of partners work through various sexual risk behaviors (i.e., frequency of sex and lack of consistent contraceptive use) to increase pregnancy risk. We also need to see if the negative relationship between pregnancy and ever having experienced sexual violence can be replicated and better understood.

\section{REFERENCES}

1. National Family Planning Board, Reproductive Health Survey 2002-2003: Jamaica Final Report, Kingston, Jamaica: National Family Planning Board, 2005

2. National Family Planning Board, Contraceptive Prevalence Survey: 1993 Jamaica Final Report, Kingston, Jamaica: National Family Planning Board, 1994.

3. Centers for Disease Control and Prevention (CDC), Highlights from the Jamaica Reproductive Health Survey, 2002-03, <http://www.cdc.gov/ reproductivehealth/Surveys/Jamaica.htm>, accessed Feb. 11, 2009.

4. Albert B, Brown S and Flanigan E, 14 and Younger: The Sexual Behavior of Young Adults (Summary), Washington, DC: National Campaign to Prevent Teen Pregnancy, 2003.

5. Zabin LS and Kiragu K, The health consequences of adolescent sexual and fertility behavior in Sub-Saharan Africa, Studies in Family Planning, 1998, 29(2):210-232.

6. Buvinic M, The costs of adolescent childbearing: evidence from Chile, Barbados, Guatemala, and Mexico, Studies in Family Planning, 1998, 29(2):201-209

7. Gigante DP et al., Risk factors for childbearing during adolescence in a population-based birth cohort in southern Brazil, Pan American Journal of Public Health, 2004, 16(1):1-10.

8. Kirby D, Antecedents of adolescent initiation of sex, contraceptive use, and pregnancy, American Journal of Health Behavior, 2002, 26(2): 473-485.

9. Jewkes R et al., Relationship dynamics and teenage pregnancy in South Africa, Social Science \& Medicine, 2001, 52(5):733-744.

10. Hof $C$ and Richters A, Exploring the intersections between teenage pregnancy and gender violence: lessons from Zimbabwe, African Journal of Reproductive Health, 1999, 3(1):51-65.

11. Martin SL et al., Sexual behaviors and reproductive health outcomes: associations with wife abuse in India, Journal of the American Medical Association, 1999, 282(20):1967-1972.

12. Manopaiboon $C$ et al., High rates of pregnancy among vocational school students: results of audio computer-assisted self-interview survey in Chiang Rai, Thailand, Journal of Adolescence, 2003, 26(5):517530

13. Maharaj P and Munthree C, Coerced first sexual intercourse and selected reproductive health outcomes among young women in Kwazulu-Natal, South Africa, Journal of Biosocial Science, 2007, 39(2): 231-244.

14. Waszak Geary C et al., Sexual violence and reproductive health among young people in three communities in Jamaica, Journal of Interpersonal Violence, 2006, 21(11):1512-1533. 
15. National Family Planning Board, Reproductive Health Survey 2002-2003: Jamaica Young Adults Report, Kingston, Jamaica: National Family Planning Board, 2005.

16. Stock JL et al., Adolescent pregnancy and sexual risk-taking among sexually abused girls, Family Planning Perspectives, 1997, 29(5):200$203 \& 227$.

17. Dickson N et al., First sexual intercourse: age, coercion, and later regrets reported by a birth cohort, BMJ, 1998, 316(7124):29-33.

18. Yimin $C$ et al., Case-controlled study on relevant factors of adolescent sexual coercion in China, Contraception, 2001, 64(2):77-80.

19. Moore K, Nord C and Peterson J, Nonvoluntary sexual activity among adolescents, Family Planning Perspectives, 1989, 21(3):110-114.

20. Koenig MA et al., Coerced first intercourse and reproductive health among adolescent women in Rakai, Uganda, International Family Planning Perspectives, 2004, 30(4):156-163.

21. Erulkar AS, The experience of sexual coercion among young people in Kenya, International Family Planning Perspectives, 2004, 30(4): 182-189.

22. Seal A, Minichiello V and Omodei M, Young women's sexual risktaking behaviour: revisiting the influences of self-efficacy and sexual self-esteem, International Journal of STD and AIDS, 1997, 8(3):159-165.

23. Olsson A et al., Sexual abuse during childhood and adolescence among Nicaraguan men and women: a population-based anonymous survey, Child Abuse and Neglect, 2000, 24(12):1579-1589.

24. Abma J, Driscoll A and Moore K, Young women's degree of control over first intercourse: an exploratory analysis, Family Planning Perspectives, 30(1):12-18

25. Blinn-Pike L et al., Is there a causal link between maltreatment and adolescent pregnancy? A literature review, Perspectives on Sexual and Reproductive Health, 2002, 34(2):68-75.

26. Boyer D and Fine D, Sexual abuse as a factor in adolescent preg nancy and child maltreatment, Family Planning Perspectives, 1992, 24(1):4-11 \& 19

27. Buzi RS et al., The impact of a history of sexual abuse on high-risk sexual behaviors among females attending alternative schools, Adolescence, 2003, 38(152):595-605.

28. Heise L, Ellsberg M and Gottemoeller M, Ending violence against women, Population Reports, 1999, Series L, No. 11.

29. Heise L, Moore K and Toubia N, Sexual Coercion and Reproductive Health: A Focus on Research, New York: Population Council, 1995.

30. Widom CS and Kuhns JB, Childhood victimization and subsequent risk for promiscuity, prostitution, and teenage pregnancy: a prospective study, American Journal of Public Health, 1996, 86(11): 1607-1612.

31. Roberts TA, Auinger P and Klein JD, Intimate partner abuse and the reproductive health of sexually active female adolescents, Journal of Adolescent Health, 2005, 36(5):380-385.

32. Gökçe B, Ozsahin A and Zencir M, Determinants of adolescent pregnancy in an urban area in Turkey: a population-based case-control study, Journal of Biosocial Science, 2006, 39(2):301-311.

33. Keddie A, Psychosocial factors associated with teenage pregnancy in Jamaica, Adolescence, 1992, 27(108):873-890.

34. World Health Organization (WHO), WHO Multi-Country Study on Women's Health and Domestic Violence against Women, Geneva: WHO, 2002.

35. WHO, Global Programme on Evidence for Health Policy, Putting Women's Safety First: Ethical and Safety Considerations for Research on Domestic Violence Against Women, Geneva: WHO, 1999.

36. Radloff LS, The CES-D scale: a self-report depression scale for research in the general population, Applied Psychological Measurement, 1977, 1(3):385-401

37. Waszak C and Wedderburn M, Baseline Community Youth Survey for VIP/Youth Project, Kingston, Jamaica: United Nations Population Fund (UNFPA), 2000.
38. Rosenberg M, Society and the Adolescent Self-Image, Princeton, NJ Princeton University Press, 1965.

39. Macy RJ et al., Partner violence among women before, during, and after pregnancy: multiple opportunities for interventions, Women's Health Issues, 2007, 17(5):290-299.

\section{RESUMEN}

Contexto: El conocimiento y uso de los anticonceptivos en la primera relación sexual han ido aumentando entre las adolescentes jamaiquinas, sin embargo, persisten las altas tasas de embarazos no planeados. Se necesita más información sobre los factores de riesgo del embarazo en adolescentes para sustentar los programas.

Métodos: Se condujo una serie de entrevistas estructuradas, con controles apareados por vecindario, en mujeres de 15-17 años de edad, 250 de las cuales estaban embarazadas en la actualidad y 500 que tenían experiencia sexual, pero nunca se habian embarazado. Se uso análisis bivariado y multivariado para examinar las asociaciones entre el embarazo adolescente y el debut sexual temprano, la coerción o violencia sexual, y las conductas de riesgo.

Resultados: Una mayor proporción de jóvenes embarazadas que sus pares que nunca se habian embarazado, habian tenido su primera relación sexual antes de la edad de 14 años (54\% vs. $41 \%$ ), una primera pareja sexual que era cinco o más años mayor (33\% vs. $20 \%$ ) y múltiples parejas (63\% vs. $50 \%$ ); una mayor proporción de las jóvenes que nunca se habian embarazado habían usado anticonceptivos en la primera relación sexual (88\% vs. 80\%). Casi la mitad (49\%) de todas las mujeres jóvenes reportaron haber experimentado alguna vez coerción o violencia sexual. Comparadas con los controles, las jóvenes embarazadas tuvieron mayores probabilidades de haber tenido una pareja mayor en la primera relación sexual y de creer que la anticoncepción es responsabilidad de la mujer ( razones de momios de 1.3 y 2.1, respectivamente), y tuvieron menores probabilidades de haber experimentado alguna vez la violencia sexual y de pensar que es importante protegerse contra el embarazo ( 0.5 y 0.2 , respectivamente). Se encontró una interacción entre el debut sexual temprano y la existencia de parejas múltiples. El haber tenido parejas múltiples se asoció con el embarazo solamente para las jóvenes con un debut sexual temprano.

Conclusiones: El alentar a las adolescentes a retrasar su debut sexual y reducir el número de parejas sexuales puede ayudar a prevenir los embarazos no planeados. Las experiencias de coerción y violencia sexuales fueron comunes en ambos grupos, destacando la necesidad de abordar la violencia basada en género a nivel de la comunidad.

\section{RÉSUMÉ}

Contexte: La connaissance et la pratique de la contraception au moment des premiers rapports sexuels se sont accrues, au fil du temps, parmi les adolescents de la Jamaïque, mais les hauts taux de grossesse non planifiée n'en persistent pas moins. Les programmes doivent être davantage informés sur les facteurs de risque des grossesses d'adolescentes. 
Méthodes: Des entretiens structurés ont été menés avec des jeunes filles de 15 à 17 ans, dont 250 enceintes au moment de l'entrevue et 500 sexuellement expérimentées mais jamais encore enceintes (groupe témoin apparié en termes de quartier). Les associations entre les grossesses d'adolescentes et l'initiation sexuelle précoce, la contrainte ou la violence sexuelle et les comportements de risque sexuel ont été examinées par analyses bi-et multivariées.

Résultats: Par rapport à celles qui ne l'avaient jamais été, plus de jeunes filles enceintes avaient connu leurs premiers rapports sexuels avant l'âge de 14 ans (54\% par rapport à 41\%), avaient eu un premier partenaire sexuel d'au moins cinq ans leur aîné (33\% par rapport à 20\%) et avaient eu plusieurs partenaires (63\% par rapport à 50\%). Plus d'adolescentes qui n'avaient jamais été enceintes avaient eu recours à la contraception lors de leurs premiers rapports sexuels (88\% par rapport à $80 \%$ ). Près de la moitié (49\%) de toutes les jeunes femmes ont déclaré avoir subi une contrainte ou violence sexuelle. Par rapport au groupe témoin, les jeunes filles enceintes présentaient une plus grande probabilité d'avoir eu un partenaire plus âgé au moment de leurs premiers rapports sexuels et de croire que la responsabilité de la contraception incombe à la femme (rapports de probabilités, 1,3 et 2,1, respectivement). Elles étaient par ailleurs moins susceptibles d'avoir subi de violence sexuel- le et de penser qu'il est important de se protéger contre la grossesse ( 0,5 et 0,2, respectivement). Une interaction a été observée entre l'initiation sexuelle précoce et la multiplicité des partenaires. Cette multiplicité ne s'est révélée associée avec la grossesse que pour les jeunes dont l'initiation sexuelle avait été précoce.

Conclusions: L'encouragement des adolescentes à différer leurs premiers rapports sexuels et à réduire le nombre de leurs partenaires sexuels peut aider à prévenir les grossesses non planifiées. L'expérience de la contrainte et de la violence sexuelle, courante dans les deux groupes, souligne la nécessité de résoudre le problème de la violence sexiste au niveau de la communauté.

\section{Acknowledgments}

The authors thank those who reviewed and provided comments on this manuscript: Debra H. Weiner, Deborah Bourne, Donna McCarraher, Barbara Janowitz and John Stanback. They also thank the South East Regional Health Authority in Jamaica for their support of the study. This study was funded through the USAID Cooperative Agreement with Family Health International (FHI) for YouthNet, No. GPH-A-00-01-00013-00. The information and views contained in this publication do not necessarily reflect those of FHI or USAID.

Author contact:JBaumgartner@fhi.org 